\title{
Promoting the use of self-management in patients with spine pain managed by chiropractors and chiropractic interns: barriers and design of a theory-based knowledge translation intervention
}

Owis Eilayyan ${ }^{1,2^{*}}$, Aliki Thomas ${ }^{1,2}$, Marie-Christine Hallé ${ }^{1,2}$, Sara Ahmed ${ }^{1,2}$, Anthony C. Tibbles ${ }^{3}$, Craig Jacobs ${ }^{3}$, Silvano Mior ${ }^{3}$, Connie Davis ${ }^{4,5}$, Roni Evans ${ }^{6}$, Michael J. Schneider ${ }^{7}$, Heather Owens ${ }^{1}$, Fadi Al Zoubi ${ }^{1,2}$, Jan Barnsley ${ }^{8}$, Cynthia R. Long ${ }^{9}$ and Andre Bussières ${ }^{1,2}$

\begin{abstract}
Background: The literature supports the effectiveness of self-management support (SMS) to improve health outcomes of patients with chronic spine pain. However, patient engagement in SMS programs is suboptimal. The objectives of this study were to: 1) assess participation in self-care (i.e. activation) among patients with spine pain, 2) identify patients' barriers and enablers to using SMS, and 3) map behaviour change techniques (BCTs) to key barriers to inform the design of a knowledge translation (KT) intervention aimed to increase the use of SMS.

Methods: In summer 2016, we invited 250 patients with spine pain seeking care at the Canadian Memorial Chiropractic College in Ontario, Canada to complete the Patient Activation Measure (PAM) survey to assess the level of participation in self-care. We subsequently conducted individual interviews, in summer 2017, based on the Theoretical Domains Framework (TDF) in a subset of patients to identify potential challenges to using SMS. The interview guide included 20 open-ended questions and accompanying probes. Findings were deductively analysed guided by the TDF. A panel of 7 experts mapped key barriers to BCTs, designed a KT intervention, and selected the modes of delivery.
\end{abstract}

Results: Two hundred and twenty-three patients completed the PAM. Approximately $24 \%$ of respondents were not actively involved in their care. Interview findings from 13 spine pain patients suggested that the potential barriers to using SMS corresponded to four TDF domains: Environmental Context and Resources; Emotion; Memory, Attention \& Decision-Making; and Behavioural Regulation. The proposed theory-based KT intervention includes paper-based educational materials, webinars and videos, summarising and demonstrating the therapeutic recommendations including exercises and other lifestyle changes. In addition, the KT intervention includes Brief Action Planning, a SMS strategy based on motivational interviewing, along with a SMART plan and reminders.

\footnotetext{
* Correspondence: owis.eilayyan@mail.mcgill.ca

${ }^{1}$ School of Physical and Occupational Therapy, McGill University, 3654

Promenade Sir-William-Osler, Montreal, Quebec H3G 1Y5, Canada

${ }^{2}$ Centre for Interdisciplinary Research in Rehabilitation of Greater Montreal

(CRIR), 6363, Hudson Road, office 061, Lindsay Pavilion of the IURDPM,

Montreal, QC H3S 1M9, Canada

Full list of author information is available at the end of the article
}

(c) The Author(s). 2019 Open Access This article is distributed under the terms of the Creative Commons Attribution 4.0 International License (http://creativecommons.org/licenses/by/4.0/), which permits unrestricted use, distribution, and reproduction in any medium, provided you give appropriate credit to the original author(s) and the source, provide a link to the Creative Commons license, and indicate if changes were made. The Creative Commons Public Domain Dedication waiver (http://creativecommons.org/publicdomain/zero/1.0/) applies to the data made available in this article, unless otherwise stated. 
(Continued from previous page)

Conclusions: Almost one quarter of study participants were not actively engaged in their spine care. Key barriers likely to influence uptake of SMS among patients were identified and used to inform the design of a theory-based KT intervention to increase their participation level. The proposed multi-component KT intervention may be an effective strategy to optimize the quality of spine pain care and improve patients' health-outcomes.

Keywords: Spine pain, Chiropractic, Self-management, Theory-based intervention, Knowledge translation, Theoretical domains framework

\section{Background}

Spine pain is a leading cause of disability and work absenteeism worldwide [1-4]. Between 50 and $80 \%$ of adults suffer from spine pain at least once during their lives $[5,6]$. Spine pain impacts both society and individuals with physical, psychological, and emotional burden [5, 7-15]. Between 1990 and 2015 the number of "years lived with disability caused by low back pain increased by $54 \% "$ [1]. The direct cost of spine pain is approximated at $\$ 6$ to $\$ 12$ billion annually in Canada [16].

Spine pain is often a chronic condition, and selfmanagement support (SMS) could reduce its consequences on patients' health [17]. Self-management is defined as an "individual's ability to manage the symptoms, treatment, physical and psychosocial consequences, and lifestyle changes inherent in living with a chronic condition" [18]. SMS strategies aimed at helping patients develop the skills they need to change negative thinking and increase physical activity $[19,20]$ are the keys to effectively manage spinal pain [21-28]. Clinical practice guidelines (CPGs) recommend SMS for patients with spine pain [29-32]. Current evidence suggests SMS has similar treatment effects compared to other more expensive and intensive approaches such as massage, acupuncture, yoga, and exercise [17, 33]. SMS helps reduce pain, disability, and psychological distress [17, 34].

Many patients with spine pain consult primary care providers including chiropractors for relief [35-37] of back and neck pain. Nearly half of these patients (median of $49.7 \%$ (interquartile range (IQR): 43.0-60.2\%)) consult specifically for low back pain or back problems, and another quarter $(22.5 \%$, IQR, $16.3-24.5 \%)$ for neck problems [37]. Among those patients seeking chiropractic care for complaints of spine pain in Canada, some consult chiropractic interns and supervisory clinicians in outpatient teaching clinics [38].

Globally, the routine use of evidence-based recommendations, including the delivery of SMS, remains suboptimal among practicing chiropractors [39-42]. Barriers among chiropractic clinicians and interns to using SMS in a large chiropractic teaching institution in Canada were previously assessed in a related qualitative study [42]. Key barriers corresponding to the theoretical domain framework (TDF) included: Knowledge; Skills;
Environmental context and resources; Emotion; Beliefs about Capabilities; Memory, attention \& decision making; and Social Influence. Patients' compliance with SMS recommendations is also suboptimal [34, 43, 44], and there is a shortage of studies that assess the barriers to the use of SMS among individuals with spine pain. Nonetheless, known barriers to implementing SMS among patients with chronic pain, low back pain, or osteoarthritis include: low self-efficacy, negative beliefs and lack of readiness to using SMS, lack of time, family commitments, poor emotional status, and poor access to information on SMS [45-47]. Poor communication between clinicians and patients also limits the use of SMS [47]. Collectively, these barriers can decrease both the utilisation of - and adherence to - SMS, and ultimately reduce its effectiveness.

Successful implementation of SMS approaches requires patients to change unhealthy behaviours and commit to healthier ones $[19,20]$, but changing individuals' behaviour is challenging [40, 48]. Therefore, it is important to assess patients' knowledge of SMS, skills, and confidence in managing their own health; a phenomenon referred to as activation level in selfcare [49]. Information on patient activation level can inform the design of appropriate strategies to support behaviour change [49]. In addition, understanding the barriers that patients face when using SMS in chiropractic contexts is necessary for successful implementation of SMS programs through theory-based Knowledge Translation (KT) interventions. The literature suggests that theory-based KT interventions can increase patients' compliance with recommended care [50], increase the likelihood of successful behaviour change [51-54], and lead to better health outcomes in different healthcare settings [55]. To date, few studies have assessed the barriers to using SMS among patients with spine pain in chiropractic teaching institutions.

The objectives of this study were to: 1) assess participation in self-care (i.e. activation) among patients with spine pain, 2) identify patients' barriers and enablers to using SMS, and 3) map behaviour change techniques (BCTs) to key barriers to inform the design of a KT intervention aimed at increasing the use of SMS. 


\section{Conceptual framework}

The Theoretical Domains Framework (TDF) was originally developed to assess the factors likely to influence professional behaviour change. The TDF has been used extensively across a range of patient populations, settings, and health conditions to understand implementation challenges [56-58], and to guide the development of theory-based KT interventions [55, 59-62]. The TDF integrates 33 theories of behaviour change and identifies 14 factors most likely to affect behaviour change: Knowledge, Skills, Social/Professional Role and Identity, Beliefs about Capabilities, Optimism, Beliefs about Consequences, Reinforcement, Intentions, Goals, Memory/Attention and Decision Processes, Environmental Context and Resources, Social Influences, Emotion, and Behavioural Regulation [63].

\section{Methods}

\section{Study design}

Three-phase mixed-methods sequential transformative design comprised of quantitative and qualitative data collection, and analyses. Ethical approval was obtained from the Research Ethics Board of both McGill University (McGill IRB: A08-E54-16B) and the Canadian Memorial Chiropractic College (CMCC-REB Approval 1512B02). Written informed consent was obtained from all participants.

\section{Setting}

The study took place at the Canadian Memorial Chiropractic College (CMCC) campus clinic and two CMCC-affiliated external teaching clinics (CMCC's Clinic at Sherbourne Health and South Riverdale Community Health Centre) in Toronto, Ontario. CMCC is the largest chiropractic teaching institution in Canada. Three other CMCC-intercity clinics were excluded because they were either not engaged in research activities or they declined to participate.

\section{Approach}

A systematic approach proposed by French et al. [55] was used to guide the development of a theory-based intervention aimed at optimizing the use of SMS among patients with spine pain. The approach includes 4 questions:

1) Who needs to do what, differently? For this question, current literature suggests that the use of SMS among patients is suboptimal [45-47]. Such a evidence-practice gap was confirmed by research team members overseeing CMCC clinical activities [64]. This question was further addressed in phase 1 of the current study which aimed to assess patient activation in SMS

(Quantitive approach).

2) Using a theoretical framework (i.e. TDF [63]), which barriers and enablers need to be addressed?

3) Which intervention components (behaviour change techniques and mode(s) of delivery) could overcome the modifiable barriers and enhance the enablers?

4) How can behaviour change be measured and understood? This question is beyond the scope of this paper and thus not addressed.

Questions 2 and 3 were addressed in two distinct phases: phase 2 aimed to identify barriers and enablers to the use of SMS (Qualitative approach). The interview data was used to inform the design of a theory-based KT intervention (phase 3). In phase 3, we mapped BCTs to relevant barriers and enablers identified in phase 2 .

\section{Phase 1: estimating patient activation (quantitative data) \\ Participants}

During the summer of 2016 we assembled a convenience sample of consecutive patients seeking care at four CMCC outpatient clinics was assembled for Phase 1. Patients had to meet the following inclusion criteria: ages of 18-70 years, currently receiving treatment from a consenting chiropractic intern, having received at least three treatment sessions for a primary back or neck pain complaint, and be able to read and hold a conversation in English.

\section{Data collection \\ Study instrument}

The Patient Activation Measure (PAM), a selfadministered 13 item questionnaire, was used to assess the level of activation in self-care among patients with spine pain [65]. The PAM divides patients into one of four activation levels (Table 1), which are associated with specific self-management and other health related behaviours [67]. The PAM is used to indicate

Table 1 "The four levels of patient activation" [66]

\begin{tabular}{ll}
\hline Level & Description \\
\hline Level 1 & $\begin{array}{l}\text { Individuals tend to be passive and feel overwhelmed } \\
\text { by managing their own health. They may not } \\
\text { understand their role in the care process. }\end{array}$ \\
Level 2 & $\begin{array}{l}\text { Individuals may lack the knowledge and confidence } \\
\text { to manage their health } \\
\text { Level 3 }\end{array}$ \\
Level 4 & $\begin{array}{l}\text { Individuals appear to be taking action but may still } \\
\text { lack the confidence and skill to support their behaviours. } \\
\text { needed to support their health but may not be able } \\
\text { to maintain them in the face of life stressors }\end{array}$ \\
\hline
\end{tabular}


the level of patient participation in SMS [65], it has been extensively tested among individuals with different health conditions, and is a reliable and valid tool $[66,68,69]$. We also asked eight additional "short answer" questions: age, gender, duration of spine pain, previous chiropractic care, SMS knowledge, Brief Action Planning (BAP) knowledge, and any existing medical comorbidities. The multiple regression analyses showed that having knowledge of SMS and knowledge of BAP were significantly associated with a higher score on the PAM. More information on the regression analysis can be found in Additional file 1 .

\section{Procedures}

Eligible patients with spine pain were identified using OSCAR [70], an electronic medical records system. Chiropractic interns were asked to recruit consecutive patients who were seeking care for spine pain. The CMCC research coordinator contacted 250 potentially interested patients. Eligible patients $(n=223)$ were verbally informed of the study aims and consented appropriately. The patients were also asked to read the online written consent form prior to completing the PAM survey questions using an iPad and computers at the clinics. Patients agreed to participate by clicking "yes" on the screen.

\section{Sample size and data analysis}

Descriptive statistics were used to obtain the PAM average total score and distribution using SAS version 9.4 (North Carolina University, USA) [71]. The total score (calibrated score 0 (no activation) - 100 (high activation)), was calculated by the Insignia Health Group (licensee of the PAM questionnaire) [66].

Sample size needed to assess the patients' participation in SMS follows the equation of $\mathrm{N} \geq(1.96)^{2} * \mathrm{SD}^{2} / \mathrm{d}^{2}$ [72]. The SD was determined based on the PAM results of previous studies $[73,74]$. The required sample size was a total of 216 subjects; $\left(1.96^{2} * 15^{2}\right) / 2^{2}$.

\section{Phase 2: identifying barriers and enablers (qualitative data)}

Subsequent to Phase 1, we conducted semi-structured individual interviews with spine pain patients in the summer of 2017. Interviewees were selected from a purposive sample of phase 1 participants. The interview guide was designed using the TDF framework [63] (See Additional file 2).

\section{Participants}

A purposive sample of patients with spine pain was assembled from two CMCC clinics, which had a larger number of patients and clinicians who were more familiar with the recruitment process. The sociodemographic characteristics of patients were similar across participating clinics. To ensure variety amongst respondents, the invitation email was sent to different groups of patients using the following criteria: age, gender and duration of spine pain.

\section{Data collection \\ Interview guide}

The interview guide was developed based on the TDF [63] to understand the patients' involvement in SMS (described in phase 1) and to identify their perceived barriers and enablers to the use of SMS. Specifically, the interview guide aimed to explore: patients' beliefs about spine pain and recovery, SMS information/tools needed and factors influencing adherence to SMS, activity limitation, exercise and physical activity, and verbal communication with their care providers. The interview guide included 20 open-ended questions, 1-2 questions per domain with accompanying probes, informed by a previous study on a related topic [75]. These questions covered 13 of the 14 TDF domains; the "Social/Professional Role and Identity" domain was excluded as it relates only to clinicians. Five KT experts and clinicians assessed the content validity of the interview guide. Each interview took approximately $30 \mathrm{~min}$.

\section{Procedures}

Thirty-eight patients attending CMCC outpatient clinics were deemed eligible to participate in the interview as they met the inclusion criteria listed under phase 1. A research assistant then contacted a purposive sample of 19 patients by email inviting them to participate in an individual interview. Online interviews were conducted with the first 13 patients who responded favourably to the invitation email. Thirteen participants is considered an appropriate sample size for achieving saturation in a theory-based interview study [76]. To assess if we achieved data saturation, we analysed the interview data for the 13 consecutive patients. No new themes emerged after the 11th interview, which confirmed that thematic saturation had been achieved.

The interviews were conducted online using Cisco $\mathrm{WebEx}^{\mathrm{Tm}}$ (Milpitas, California (United States)) by the research assistant (MSc degree) who had previous experience in facilitating interviews based on the TDF. All interviews were audio recorded, transcribed verbatim and anonymized. All participants completed and signed an informed consent form prior to the interview.

\section{Data analysis}

Two assessors independently coded each transcript deductively. The assessors met three times online to compare the results. Disagreements were formally resolved by a third team member $(\mathrm{AB})$. The analysis was similar 
to the one used by the research team in prior studies of chiropractors [62, 77]. Briefly, each transcript was divided into different statements (unit of meaning), after which each statement was coded into relevant TDF domains onto an Excel spreadsheet. Statements were then linked to specific beliefs. A specific belief is defined as "a core statement that captures a common theme from multiple response statements and provides detail about the role of a given domain in influencing practice behaviour" $[62,78]$. The specific beliefs were classified into one of 3 categories: likelihood to either increase (facilitator), decrease (barrier), or have no influence on the use of SMS. The most important key barriers were identified as: considering frequency of belief, importance of the belief, and contrasting beliefs.

\section{Phase 3: intervention design}

The aim of phase 3 was to design a KT intervention to address previously identified barriers from phase 2 using intervention mapping.

\section{Participants}

Seven research team members attended a half-day online meeting. Members included three KT experts, one patient representative, and three CMCC faculty members: a health services researcher, the Dean of Clinics, and a person overseeing curricular development. All CMCC faculty members were familiar with the TDF and BCTs.

\section{Procedure}

Guided by established methods for designing KT interventions based on TDF-informed problem analysis $[56,79,80]$, three team members (AB, AT, OE) mapped the key TDF barriers identified in Phase 2 onto relevant BCTs. Intervention components corresponding to the selected BCTs that could potentially address the key barriers were considered and selected $[42,62]$. The remaining team members were then provided with the overall findings (i.e. key barriers and mapping exercise) in advance of a group meeting and asked to review each step, before recommending other potentially effective KT intervention components. Based on the available evidence of the effectiveness of BCTs [81-84] and the ease of implementation of such interventions into clinical settings (e.g., extent to which the proposed intervention is deemed to be acceptable, appropriate, and feasible) [85], the group reached a consensus on the preferred $\mathrm{KT}$ intervention components and modes of delivery (e.g. paper-based/electronic format).

The resultant selected KT interventions aimed mainly to facilitate the implementation of SMS guided by the BAP technique [86]. The BAP was developed based on motivational interviewing [86], and has been used in different clinical settings and integrated into the curricula of several medical training programs to enable the utilisation of SMS [86, 87]. Furthermore, BAP could be an ideal SMS program for the busy clinician [86]. The BAP technique includes three questions and five skills including the "offering of a behavioral menu, SMART planning, eliciting a commitment statement, problem solving for low confidence, and follow up" [88]. The technique consists of engaging a dialogue between the patient and healthcare providers in order to help patients take care of their own health.

\section{Results}

Phase 1-PAM survey

Data were collected from 223 of 250 (89.2\% response rate) spine pain patients. The majority of respondents were female $(n=125 / 219 ; 57.1 \%)$, with a mean age of 49.4 years $(\mathrm{SD}=14.1)$. Nearly $80 \%(n=175 / 219)$ reported having spine pain greater than 1 year in duration (Table 2). The average PAM score was $64.5(\mathrm{SD}=12.9)$, suggesting a good level of activation. While respectively $103 / 219(47 \%)$ and 64/219 (29.2\%) participants reported scores corresponding to the third and fourth levels (i.e., high activation level), approximately a quarter $(n=52 / 219,23.7 \%)$ of participants were in the first or second levels (low activation level). The raw data are presented in Additional file 3.

\section{Phase 2-interviews \\ Characteristics of participants interviewed}

The 13 interviewed participants had a mean age of $48 \pm 15.6$ years (range 23-67 years); 61\% (8/13) were women, and their average duration of spine pain was $13.8 \pm 14.7$ years.

Table 2 Survey Participants Characteristics $(n=219)$

\begin{tabular}{ll}
\hline Variable & Mean (SD), N (\%) \\
\hline Age & $49.4(14.1)$ \\
Gender, women & $125 / 219(57.1 \%)$ \\
Duration of Spine Pain: < 1 year & $44 / 219(20.1 \%)$ \\
$>1$ year & $175 / 219(79.9 \%)$ \\
Received Previous Chiropractic Care (yes) & $169 / 219(77.2 \%)$ \\
Medical conditions beside back/neck pain (yes) & $138 / 218(63.3 \%)$ \\
PAM score & $64.5(12.9)$ \\
PAM Activation Levels: Level 1 & $19 / 219(8.7 \%)$ \\
Level 2 & $33 / 219(15.1 \%)$ \\
Level 3 & $103 / 219(47 \%)$ \\
Level 4 & $64 / 219(29.2 \%)$
\end{tabular}

PAM patient activation measure 


\section{Key themes identified within relevant domains}

We identified 457 statements representing 44 specific beliefs and 20 themes (see Additional file 4). Additional file 5 provides interviewees' quotes categorized by specific domains and beliefs. Five key TDF domains were presumed to have an important influence on the targeted behaviour: 1) Environmental Context and Resources; 2) Emotion; 3) Memory, Attention \& Decision Making; 4) Behavioural Regulation; and 5) Knowledge.

\section{Phase 3-intervention design}

Different BCTs were mapped to key relevant domains, and $\mathrm{KT}$ intervention components and actions were proposed based on those BCTs (Table 3). Based on effectiveness and feasibility considerations, team members agreed on the modes of delivery for the KT intervention.

\section{Key TDF domains (phase 2) and proposed KT intervention components (phase 3)}

In this section, we first present the key TDF domains with the corresponding specific beliefs and themes (Phase 2). Next, we mapped the BCTs onto these key domains and the corresponding intervention components proposed by the team members (Phase 3). Table 4 summarizes the key TDF domains and proposed KT intervention.

\section{Environmental context and resources}

Ninety statements were associated with Environmental Context and Resources domain. These statements corresponded to 11 specific beliefs that were summarized under 5 themes: 1) time; 2) surrounding environment; 3) cost; 4) communication with clinicians; and 5) resources. Related to this domain, interviewees identified several barriers to using SMS including lack of time, lack of energy, work environment, and lack of educational materials. Interviewees also identified facilitators such as home environment, cooperation of clinicians, and receiving educational materials. All interviewees agreed that receiving educational/supportive materials on exercises would be helpful in adhering to SMS. However, about half of interviewees (7/13) said they had received educational materials from their treating interns. Most of the interviewees $(10 / 13)$ indicated that they had difficulty performing exercises at work given the lack of space, and (6/13) stated that they would be able to do the exercises at home.

BCTs that were mapped to this domain included environmental changes and time management. For instance, providing patients with either paper-based or online handouts that describe and demonstrate relevant recommendations such as exercises or other life-style changes could help address this barrier. In addition, patients could be encouraged to seek advice from their intern/clinician on ways to manage their time so they may use SMS more efficiently. This could be offered by interns/clinicians during patient visits while using BAP, an intervention based on motivational interviewing.

\section{Emotion}

Thirty-one statements were mapped to the domain of Emotion. These statements represented 5 specific beliefs and were categorized under one theme: emotion concerning the use of SMS. More than half of interviewees (7/13) agreed that SMS made them feel good, though some interviewees stated that performing exercises, as a SMS component, sometimes exacerbated their pain and made them feel frustrated and anxious. Two patients felt anxious about not performing the exercises properly.

Stress management and social support (emotional) were identified as BCTs to address the barriers related to emotion. The intervention components proposed to implement these BCTs included: 1) providing the patients with educational/supportive materials (handout) on the use of SMS, and 2) encouraging patients to share successful strategies for reducing anxiety with other patients.

\section{Memory, attention \& decision making}

Sixty-two statements pertained to the domain of Memory, Attention \& Decision Making. These statements corresponded to 4 specific beliefs and 3 themes: ability to make a decision to use SMS, participating in decisionmaking on SMS, and remembering to use SMS. Almost half of interviewees (6/13) stated that remembering to use SMS regularly was challenging. Furthermore, almost all interviewees (12/13) preferred to be involved in their own clinical decision-making, as this may have motivated them to use SMS. They indicated that being involved in decision making would increase their adherence to SMS recommendations. Almost all interviewees (11/13) mentioned that they were very/somewhat involved in decisions about treatment options for SMS.

BCTs identified for this domain were planning/implementation; prompts/triggers/cues; and motivational interviewing. The suggested BAP technique could be led by the intern/clinician and used to deliver such BCTs to encourage patients to be more involved in the decision-making process. The BAP technique also provides patients with strategies to help them to remember to use and integrate SMS into their daily life.

\section{Behavioural regulation}

Forty-two statements were mapped to the Behavioural Regulation domain. These statements represented 3 specific beliefs forming one overarching theme: self-management is a part of patients' routine. Most of the interviewees stated 
Table 3 Mapping behaviour change techniques on key domains, proposed KT interventions and actions

\begin{tabular}{ll}
\hline Self-management-TDF barriers (BCTs) & KT Intervention \\
\hline Knowledge & - Standardized materials as tools to \\
- Patients believe that they know & introduce the concept of SMS \\
enough about SMS & \\
Behavioural change techniques: & \\
Information regarding behaviour, & \\
outcome. &
\end{tabular}
Actions

- Context: the majority of patients believe that exercise is the

core component of self-management strategies (SMS)

- Aim: to introduce and maximize the patients' knowledge on SMS

- Opportunities:

- Distribute educational materials to patients summarizing the components of SMS, and emphasizing ways to initiate/sustain life style changes

- Webinar to provide information on SMS

- Provide information on SMS on social media (e.g. Facebook)

Environmental Context and

Resources

- Lack of time to use self-management among patients

- Not receiving educational materials

Behavioural change techniques:

(Environmental Changes; Time management)

Emotion

- Feeling of anxiety/ frustrating

regarding use SMS

Behavioural change techniques:

(Stress Management, Social

support (emotional); Coping strategies)

Memory, attention \& decision making

- Few patients were not involved in the decision making

- Remembering to do SMS is challenging

Behavioural change techniques:

planning/implementation; Prompts/

Triggers/Cues; Motivational Interviewing
- Standardized electronic or printed materials as tools for facilitating the use of SMS

- Persuasive communication

- Modeling, demonstration of behaviour by others

- Context: Lack of time is a barrier to using SMS

- Aim: helping patients better manage their time to use SMS

- Opportunity:

- Encouraging patients to seek advice from clinicians/interns on ways to manage their time to be able to use SMS (before going to work/school, at lunch time, going to the gym ...)

- Provide patients with educational materials (paper based and e-pamphlets) summarizing the key components of self-management

- Webinar and videos to provide information on SMS

- Context: patients stated that they have some anxiety and concern regarding performing therapeutic exercises improperly

- Aim: minimizing the anxiety among patients by providing them with materials summarizing the prescribed exercises

- Opportunities:

- Webinar and videos to provide information about the SMS and to demonstrate home exercises

- Having them speak to other patients who have been successful $\checkmark$ create a patient video to share stories on successful strategies on how to integrate SMS into daily schedule

- Persuasive communication and information regarding behavioural outcomes

- Provision of information

- Instructions

- Reminders

- Context: Some patients were not involved in the decision making process. Many patients have difficulty in remembering the SMS components

- Aim: to facilitate the involvement of patients in the decision making process, and to remind patients about the use of SMS - Opportunities:

- Distribute educational/instructional materials to patients to facilitate the shared decision making

- Encourage patients to be actively involved in the decision making process by using the principles of BAP

- Webinar to provide suggestions on ways of implementing SMS

- Social media to provide information on SMS

- Send patients reminders to use SMS via:

- E-mail

- Phone call (ex. when confirming next appointment)

Behavioural Regulation

- Some patients don't use SMS as much as they should

Behavioural change techniques:

planning/implementation; Prompts/

Triggers/Cues
- Reminders
- Persuasive communication

- Context: Some patients do not use SMS as often as they should

- Aim: to understand why they don't and motivate patients to use SMS

more regularly

- Opportunities:

- Encourage clinicians/interns to help patients form a SMART

plan to self-manage

- Encourage patients to put Post-it notes near their computer automated recalls on their cell phone and/or lap-top

- Send patients reminders to use SMS via:

- E-mail

- Phone cal

$B A P$ brief action planning, $B C T$ behavioural change technique, $K T$ knowledge translation, $S M S$ self-management strategy

that they were integrating SMS into their routine. However, 8 out of 13 interviewees indicated that they did not use SMS as much as they could have because of lack of time, work commitments, feeling lazy, and forgetting to use SMS.
The BCTs and interventions mapped to this domain were similar to the ones mapped for the "Memory, Attention E Decision Making” domain. BAP technique emphasizing the SMART (Specific, Measurable, Attainable, 
Table 4 The key TDF domains and proposed KT intervention

\begin{tabular}{|c|c|c|}
\hline Self-management-TDF barriers & Description & Proposed $\mathrm{KT}$ intervention \\
\hline $\begin{array}{l}\text { Knowledge } \\
\text { - Patients believe that they know enough } \\
\text { about SMS }\end{array}$ & $\begin{array}{l}\text { - Context: the majority of patients believe } \\
\text { that exercise is the core component } \\
\text { of self-management strategies (SMS) }\end{array}$ & $\begin{array}{l}\text { - Distribute educational materials to patients summarizing the } \\
\text { components of SMS, and emphasizing ways to initiate/ } \\
\text { sustain life style changes } \\
\text { - Webinar to provide information on SMS } \\
\text { - Provide information on SMS on social media (e.g. Facebook) }\end{array}$ \\
\hline $\begin{array}{l}\text { Environmental Context and Resources } \\
\text { - Lack of time to use self-management } \\
\text { among patients } \\
\text { - Not receiving educational materials }\end{array}$ & - Lack of time was a barrier to using SMS & $\begin{array}{l}\text { - Encourage patients to seek advice from clinicians/interns on } \\
\text { ways to manage their time to be able to use SMS (before } \\
\text { going to work/school, at lunch time, going to the gym ...) } \\
\text { - Provide patients with educational materials (paper based and } \\
\text { e-pamphlets) summarizing the key components } \\
\text { of self-management } \\
\text { - Webinar and videos to provide information on SMS }\end{array}$ \\
\hline $\begin{array}{l}\text { Emotion } \\
\text { - Feeling of anxiety/ frustration regarding } \\
\text { use SMS }\end{array}$ & $\begin{array}{l}\text { - Patients stated that they have some } \\
\text { anxiety and concern regarding } \\
\text { performing therapeutic exercises } \\
\text { adequately }\end{array}$ & $\begin{array}{l}\text { - Webinar and videos to provide information about the SMS } \\
\text { and to demonstrate home exercises } \\
\text { - Have patients speak to other patients who have been } \\
\text { successful } \\
\checkmark \text { create a patient video to share stories on successful } \\
\text { strategies on how to integrate SMS into daily schedule }\end{array}$ \\
\hline $\begin{array}{l}\text { Memory, attention \& decision making } \\
\text { - Few patients were not involved in the } \\
\text { decision making } \\
\text { - Remembering to do SMS is challenging }\end{array}$ & $\begin{array}{l}\text { - Some patients were not involved in } \\
\text { the decision making process. Many } \\
\text { patients had difficulty in remembering } \\
\text { the SMS components }\end{array}$ & $\begin{array}{l}\text { - Distribute educational/instructional materials to patients to } \\
\text { facilitate the shared decision making } \\
\text { - Encourage patients to be actively involved in the decision } \\
\text { making process by using the principles of BAP } \\
\text { - Webinar to provide suggestions on ways of implementing } \\
\text { SMS } \\
\text { - Social media to provide information on SMS } \\
\text { - Send patients reminders to use SMS via: } \\
\text { - E-mail } \\
\text { - Phone call (ex. when confirming next appointment) }\end{array}$ \\
\hline $\begin{array}{l}\text { Behavioural Regulation } \\
\text { - Some patients don't use SMS as much } \\
\text { as they should }\end{array}$ & $\begin{array}{l}\text { - Some patients did not use SMS } \\
\text { as often as they should }\end{array}$ & $\begin{array}{l}\text { - Encourage clinicians/interns to help patients form a } \\
\text { SMART plan to self-manage } \\
\text { - Encourage patients to put Post-it notes near their } \\
\text { computer, automated recalls on their cell phone and/ } \\
\text { or lap-top } \\
\text { - Send patients reminders to use SMS via: } \\
\text { - E-mail } \\
\text { - Phone call }\end{array}$ \\
\hline
\end{tabular}

Relevant, and Timely) goal setting approach can help patients create an action plan for routinely using SMS. In addition, reminder strategies were proposed to prompt patients to use SMS, including post-it notes placed near their computer, and automated recall messaging on their cell phone and/or lap-top. To facilitate self-monitoring, patients could also be invited to keep a journal or log their activity between visits.

\section{Knowledge}

Sixty-two statements were linked to the Knowledge domain. These statements represented 4 specific beliefs and collapsed into 2 themes: awareness of, and knowledge about SMS. All interviewees confirmed that they were aware of SMS and had sufficient information about it. However, interviewees tended to primarily focus on exercise, disregarding other components of SMS (e.g. lifestyle changes).

Information regarding behaviour was the BCT mapped to this domain. Patients identified the need to receive more information regarding SMS. The interventions proposed included distributing educational materials that summarized the key elements of SMS and emphasized ways to initiate/sustain lifestyle changes, as well as webinars and social media (e.g. Facebook) that would provide information on SMS.

\section{Selection of the final knowledge translation (KT) intervention}

Drawing upon current evidence for the effectiveness of different KT strategies [89] and BCTs [90] and the understanding of the feasibility of implementing interventions in the CMCC clinics, the research team members considered intervention components that would facilitate the use of SMS among patients with spine pain. They reached consensus on the following intervention components and modes of delivery:

I. Provide patients with supportive handouts summarising and demonstrating the therapeutic 
recommendations including exercises and other lifestyle changes.

a. Paper-based

b. Online: webinars or social media (e.g. Facebook)

c. Videos

II. Create short videos for patients to share stories on their successful strategies and how they integrated SMS into their daily routine.

III. Implement a BAP program based on motivational interviewing led by interns/clinicians. This includes:

a. SMART goal setting approach

b. Advice on managing time

c. Decision making process

d. Reminder strategies

\section{Discussion}

SMS programs aim to empower and prepare patients to take charge of their own health condition [91]. SMS can help decrease pain levels and improve physical function among patients with spine pain [17]. Our PAM survey results indicated that three-quarters of participants were already at a higher level of activation (Levels $3 \& 4$ ), while one quarter of participants were at a lower level of activation (Levels 1 \& 2). Patients with high levels of activation need to be encouraged to continue adhering to SMS, whereas patients with low levels need help to increase their knowledge, motivation and self-efficacy in order to initiate behaviour change through the guidance of their healthcare provider. Highly activated patients are more likely to have positive health outcomes and lower health costs, and adopt new healthy behaviours [49]. In addition, a higher activation level is an indicator of patient adherence to SMS [49]. Level 3 suggests that although patients are changing their lifestyle, they still lack the confidence and skills to support such changes [49], while Level 4 indicates that the patients have already changed their lifestyle to support their condition, but this change may not be adequately maintained [49]. According to Hibbard and Gilburt (2014), the strategy needed for individuals in Levels 3 or 4 involves helping them adopt a new behaviour, and gain sufficient knowledge, confidence, and skills to be able to adopt and maintain the behaviour [49]. In addition, these patients need assistance to problem solve in difficult situations in order to maintain newly adopted behaviours [49]. On the other hand, people who have lower levels of PAM (i.e. levels 1 \& 2) need assistance to understand their active role in the health care and increase their knowledge and confidence to participate in their health management [49]. These proposed strategies are consistent with the components of the interventions selected by our expert panel to address the identified barriers and help patients with chronic spine pain adhere to SMS.

In our study, we found that the adherence to SMS was influenced by barriers corresponding to 5 domains of the TDF, namely: Environmental context and resources, Emotion, "Memory, Attention \& Decision Making", Behavioural Regulation, and Knowledge. We identified two unique barriers that have not been previously identified, namely: "Memory, Attention \& Decision Making" and "Behavioural Regulation". In order to address the five aforementioned barriers, a panel of experts mapped BCTs to each barrier and selected the appropriate intervention components.

An additional barrier identified by interviewees was not having enough time to use SMS because of their various school, work and life commitments. This finding is consistent with May (2010) who showed that time and family commitments are external factors that restricted patients with spine pain from using SMS [45]. Half of interviewees expressed an interest in receiving supportive materials on SMS (describing the prescribed exercise), despite all of them confirming they had sufficient knowledge of SMS. However, interviewees focused only on exercise while disregarding other components of SMS (i.e. lifestyle changes). Poor access to information, not receiving effective information, or lack of support from clinicians regarding SMS are factors that have been reported to restrict the use of SMS among patients [45-47]. Therefore, providing patients with time management strategies and educational materials (e.g., paper based and e-pamphlets) summarizing the key components of SMS may provide further information on SMS and promote adherence to SMS [92, 93].

Poor mental health and low self-efficacy have been identified as internal factors restricting patient uptake of SMS [45]. Some interviewees indicated feeling anxious when performing therapeutic exercises, especially if they were unsure of how to perform them properly. Developing videos that demonstrate the prescribed home exercises may increase patients' confidence to appropriately perform the exercises without supervision and reduce the likelihood of anxiety [94] toward SMS. In addition, having an online discussion board for patients may assist in reducing their anxiety through the sharing of helpful strategies and stories.

Although most interviewees confirmed they felt somewhat involved in the decision-making process, the majority indicated that they wanted to be much more involved in their treatment plan. Patients tend to value clinicians' advice and recommendations [95], 
thus effective clinician-patient communication on health issues and setting treatment goals together may empower patients to adhere to their treatment plan, which may in turn increase their satisfaction with care and improve health outcomes (e.g. pain, functional ability, and emotional well-being) [96, 97]. Effective communication between patients and clinicians is an important component of SMS [98].

Lastly, interviewees indicated they felt confident and skilled to use SMS, believed in the benefits of SMS, intended to continue using SMS, and perceived SMS as an important approach to dealing with spine pain. This finding might be attributed to the fact that our study interviewees were already involved in, and may have benefited from, SMS. This could also explain why interviewees were optimistic about, and intended to use, SMS. These findings will facilitate the implementation of SMS among patients with spine pain in participating clinics as these patients are encouraged to be involved in SMS.

The expert panel suggested different $\mathrm{KT}$ intervention components based on BCTs to address the identified barriers to using SMS among spine pain patients. The selected KT intervention components formed a multifaceted theory-based program that could be implemented in addressing more than one barrier simultaneously [99]. Importantly, the KT intervention com ponents (educational materials, webinar, videos that were developed by The CCGI (https://www.youtube. com/channel/UCduMXDBP76INn85Il9fQ3qg/playlists?view $=50 \&$ shelf_id $=2 \&$ sort $=$ dd), BAP motivational interviewing, reminders, and use of social media) were selected based on the feasibility of their implementation within the respective clinical setting and evidence of their effectiveness. For example, a 2016 systematic review on patient-mediated knowledge translation interventions found educational materials can improve patients' knowledge and support decision making [92]. Furthermore, Coudeyre et al. (2006) showed that using written materials with patients significantly improved their functional status and knowledge of spine pain [93]. Mahler (1999) reported that using videos as an educational tool improved treatment adherence to the exercise prescribed [100]. According to a logic model describing the effect of social media on behaviours, participation on social media may increase patient's intention to adopt healthy behaviours, which in turn may lead to changes in behaviour and improvements in health outcomes [101]. Lastly, systematic reviews show that implementing multicomponent interventions (education, feedback, motivational intervening, counselling, and/or reminders) improves adherence to prescribed medications in different health conditions [102-104].
While CMCC promotes sustainable use of evidencebased practices (EBP) among graduates, a structured approach to SMS that allows for patient-centered goals is not yet integrated into the curriculum [105]. To promote the use of SMS at CMCC, the intervention targeting patients will be integrated with the theory-based KT intervention in order to enhance the use of SMS among clinicians and interns. The KT intervention designed in a parallel study by our expert panel (3 KT researchers, a researcher in medical education, 2 CMCC faculty members, and one patient representative) is composed of a webinar and online educational module on a SMS guided by the Brief Action Planning, clinical vignettes, training workshop, and opinion leader support [42]. We used the BAP framework to guide our SMS, which has been shown to enable its use $[86,87]$. The use of SMS, guided by an action plan such as the BAP framework, has also been shown to improve patients' adherence to recommended care [81] and health outcomes [98].

\section{Limitations}

Our study has some limitations. We conducted the study in a large chiropractic teaching institution and as such, the results may not be generalized to all chiropractic private practice. Also, to keep interviews within a reasonable length, only 1 to 2 questions were used in the interviews to cover each of the TDF domains. As a consequence of this short interview format, the results may fail to capture the essence of each domain. Lastly, for the individual interview phase, only participants who responded to the invitation email were interviewed, these participants may not have been representative of the all study participants.

\section{Conclusions}

Approximately a quarter of respondents seeking care for spine pain in chiropractic teaching clinics reported a lower level of activation in SMS. Theoretical barriers likely to influence the uptake of SMS among interviewed patients included: Environmental Context and Resources; Memory, Attention E Decision-Making; Emotion; and Behavioural Regulation. These findings informed the design of a multicomponent theorybased tailored KT intervention to optimize the quality of spine pain care and improve patients' health outcomes.

\section{Additional files}

Additional file 1: "Regression analysis and output". It provides information about the regression analysis that was conducted to assess the influence of patients' characteristics and patient activation. It also shows the output of the regression analysis. (DOCX $15 \mathrm{~kb}$ ) 
Additional file 2: "Barriers and facilitators to adherence of SMS among patients with back and neck pain - Interview topic guide". It provides the interview guide for individual interviews with patients. (DOCX $19 \mathrm{~kb}$ )

Additional file 3: "PAM survey - raw patient data". An Excel sheet provides the raw data for patients surveyed in phase 1 using the PAM instrument. (XLSX $53 \mathrm{~kb}$ )

Additional file 4: "Thematic analysis based on the TDF". It provides number of patients' statements for each TDF domain, TDF specific beliefs and themes. (DOCX $19 \mathrm{~kb}$ )

Additional file 5: "Specific Beliefs for each TDF with illustrative quotes". It provides patient quotes representing specific TDF domains and beliefs. (DOCX $18 \mathrm{~kb}$ )

\section{Abbreviation}

BAP: Brief action planning; BCT: Behavioural change technique; CCGI: Canadian Chiropractic Guideline Initiative; CMCC: Canadian Memorial Chiropractic College; CPGs: Clinical practice guidelines; IQR: Interquartile range; KT: Knowledge translation; PAM: Patient activation measure; SMS: Selfmanagement strategy; TDF: Theoretical domain framework

\section{Acknowledgements}

We acknowledge CMCC and CCGI for their support in conducting this research project.

\section{Authors' contributions}

$\mathrm{OE}$ and $\mathrm{HO}$ conducted the individual interviews. OE analysed the quantitative data, while $\mathrm{OE}$ and $\mathrm{HO}$ analysed the qualitative data under the supervision of $A B$ and $A T$ (principal investigators). $O E, A B, A T, C J, A C T, C D$, $S M, F A$, and JB contributed to the design of Knowledge Translation intervention. All authors: $O E, A B, A T, M C H, C J, A C T, C D, H O, F A, J B, S A, S M$, $\mathrm{RV}, \mathrm{MJC}$ and $\mathrm{CL}$ contributed to the preparation of the manuscript. All authors have read and approved the manuscript.

\section{Funding}

Canadian Chiropractic Guideline Initiative. The funding body did not influence the study design, analysis, and results.

\section{Availability of data and materials}

The raw data that support the conclusions of this manuscript is available in the Additional file 3. The interview data are available in Additional files 4 and 5

\section{Ethics approval and consent to participate}

Ethical approval was obtained from the Research Ethics Board of both McGill University (McGill IRB: A08-E54-16B) and the Canadian Memorial Chiropractic College (CMCC REB Approval 1512B02), and written informed consent was obtained from all participants.

\section{Consent for publication}

Not Applicable

\section{Competing interests}

The authors declare that they have no competing interests.

\section{Author details}

${ }^{1}$ School of Physical and Occupational Therapy, McGill University, 3654 Promenade Sir-William-Osler, Montreal, Quebec H3G 1Y5, Canada. ${ }^{2}$ Centre for Interdisciplinary Research in Rehabilitation of Greater Montreal (CRIR), 6363, Hudson Road, office 061, Lindsay Pavilion of the IURDPM, Montreal, QC H3S 1M9, Canada. ${ }^{3}$ Canadian Memorial Chiropractic College, 6100 Leslie St, North York, ON M2H 3J1, Canada. ${ }^{4}$ University of British Columbia, 2329 West Mall, Vancouver, BC V6T 1Z4, Canada. ${ }^{5}$ Centre for Collaboration, Motivation and Innovation, PO Box 1343, Vernon, BC V1T 6N6, Canada. ${ }^{6}$ University of Minnesota, Minneapolis, MN 55455, USA. ${ }^{7}$ University of Pittsburgh, 4200 Fifth Ave, Pittsburgh, PA 15260, USA. ${ }^{8}$ University of Toronto, 27 King's College Cir, Toronto, ON M5S, Canada. ${ }^{9}$ Palmer College, Davenport, 1000 Brady St, Davenport, IA 52803, USA.
Received: 8 March 2019 Accepted: 5 July 2019

Published online: 16 October 2019

\section{References}

1. Hartvigsen J, Hancock MJ, Kongsted A, Louw Q, Ferreira ML, Genevay S, Hoy D, Karppinen J, Pransky G, Sieper J, et al. What low back pain is and why we need to pay attention. Lancet. 2018;391(10137):2356-67.

2. Vos T, Flaxman AD, Naghavi M, Lozano R, Michaud C, Ezzati M, Shibuya K, Salomon JA, Abdalla S, Aboyans V, et al. Years lived with disability (YLDs) for 1160 sequelae of 289 diseases and injuries 1990-2010: a systematic analysis for the global burden of disease study 2010. Lancet. 2012;380:2163-96.

3. Hoy D, March L, Brooks P, Woolf A, Blyth F, Vos T, Buchbinder R. Measuring the global burden of low back pain. Best Pract Res Clin Rheumatol. 2010;24:155-65.

4. Johannes CB, Le TK, Zhou X, Johnston JA, Dworkin RH. The prevalence of chronic pain in United States adults: results of an internet-based survey. J Pain. 2010;11:1230-9.

5. De Souza L, Frank A. Conservative management of low back pain. Int J Clin Pract. 2001;55:21-31

6. WHO: The burden of musculoskeletal conditions at the start of the new millennium. World Health Organ Tech Rep Ser 2003, 919:i-x, 1-218, back cover.

7. Andersson GBJ. Epidemiological features of chronic low-back pain. Lancet. 1999;354:581-5.

8. Scheermesser M, Bachmann S, Schamann A, Oesch P, Kool J. A qualitative study on the role of cultural background in patients' perspectives on rehabilitation. BMC Musculoskelet Disord. 2012;13:5.

9. Almeida DB, Poletto PH, Milano JB, Leal AG, Ramina R. Is preoperative occupation related to long-term pain in patients operated for lumbar disc herniation? Arq Neuropsiquiatr. 2007;65:758-63.

10. Chin KR, Tomlinson DT, Auerbach JD, Shatsky JB, Deirmengian CA. Success of Lumbar Microdiscectomy in Patients With Modic Changes and Low-back Pain: A Prospective Pilot Study. J Spinal Disord Tech. 2008;21:139-44. https://doi.org/10.1097/BSD.1090b1013e318093e318095dc.

11. Horng Y-S, Hwang Y-H, Wu H-C, Liang H-W, YJ MHE, Twu F-C, Wang J-D Predicting Health-Related Quality of Life in Patients With Low Back Pain. Spine. 2005;30:551-5. https://doi.org/10.1097/1001.brs.0000154623.000012 0778.f0000154620

12. Kim T-S, Pae C-U, Hong C-K, Kim J-J, Lee C-U, Lee S-J, Paik I-H, Lee C. Interrelationships among pain, disability, and psychological factors in young Korean conscripts with lumbar disc herniation. Mil Med. 2006;171:1113-6.

13. Mannion AF, Dvorak J, Muntener M, Grob D. A prospective study of the interrelationship between subjective and objective measures of disability before and 2 months after lumbar decompression surgery for disc herniation. Eur Spine J. 2005;14:454-65.

14. Di lorio A, Abate M, Guralnik JM, Bandinelli S, Cecchi F, Cherubini A, Corsonello A, Foschini N, Guglielmi M, Lauretani F, et al. From chronic low back pain to disability, a multifactorial mediated pathway: the InCHIANTI study. Spine (Phila Pa 1976). 2007;32:E809-15.

15. Hicks GE, Simonsick EM, Harris TB, Newman AB, Weiner DK, Nevitt MA, Tylavsky FA. Trunk muscle composition as a predictor of reduced functional capacity in the health, aging and body composition study: the moderating role of back pain. J Gerontol A Biol Sci Med Sci. 2005;60:1420-4

16. Brown A, Angus D, Chen S, Tang Z, Milne S, Pfaff J, Li H, Mensinkai S. Costs and outcomes of chiropractic treatment for low Back pain. Ottawa: Canadian Coordinating Office for Health Technology Assessment; 2005.

17. Oliveira VC, Ferreira PH, Maher CG, Pinto RZ, Refshauge KM, Ferreira ML. Effectiveness of self-management of low back pain: systematic review with meta-analysis. Arthritis Care Res (Hoboken). 2012;64:1739-48.

18. Mayo N: Dictionary of Quality of Life and Health Outcomes Measurement. (Mayo N ed., 1st edition. pp. 129: ISOQOL; 2015:129.

19. Hanson R, Gerber K. Coping with chronic pain: a guide to patient selfmanagement. NewYork: Guilford Press; 1990.

20. Dennis C. Turk, Meichenbaum D, Myles G: Pain and Behavioral Medicine: A Cognitive-Behavioral Perspective. New York: The Guilford Press; 1983.

21. Bertozzi L, Gardenghi I, Turoni F, Villafane JH, Capra F, Guccione AA, Pillastrini P. Effect of therapeutic exercise on pain and disability in the management of chronic nonspecific neck pain: systematic review and meta-analysis of randomized trials. Phys Ther. 2013;93:1026-36.

22. Von Korff M, Crane P, Lane M, Miglioretti DL, Simon G, Saunders K, Stang P, Brandenburg N, Kessler R. Chronic spinal pain and physical-mental 
comorbidity in the United States: results from the national comorbidity survey replication. Pain. 2005;113:331-9.

23. Ritzwoller DP, Crounse L, Shetterly S, Rublee D. The association of comorbidities, utilization and costs for patients identified with low back pain. BMC Musculoskelet Disord. 2006;7:72

24. Hartvigsen J, Natvig B, Ferreira M. Is it all about a pain in the back? Best Pract Res Clin Rheumatol. 2013;27:613-23.

25. Sallis R, Franklin B, Joy L, Ross R, Sabgir D, Stone J. Strategies for promoting physical activity in clinical practice. Prog Cardiovasc Dis. 2015;57:375-86.

26. Marzolini S, Oh PI, Alter D, Stewart DE, Grace SL. Musculoskeletal comorbidities in cardiac patients: prevalence, predictors, and health services utilization. Arch Phys Med Rehabil. 2012;93:856-62.

27. Bodenheimer T, MacGregor K, Sharifi C. Helping patients manage their chronic conditions. Oakland, California: California HealthCare Foundation; 2005

28. Gore M, Sadosky A, Stacey BR, Tai KS, Leslie D. The burden of chronic low back pain: clinical comorbidities, treatment patterns, and health care costs in usual care settings. Spine (Phila Pa 1976). 2012;37:E668-77.

29. Stochkendahl MJ, Kjaer P, Hartvigsen J, Kongsted A, Aaboe J, Andersen M, Andersen MO, Fournier G, Hojgaard B, Jensen MB, et al. National Clinical Guidelines for non-surgical treatment of patients with recent onset low back pain or lumbar radiculopathy. Eur Spine J. 2017;27(1):60-75.

30. National Guideline C: National Institute for health and care excellence: clinical guidelines. In Low Back Pain and Sciatica in Over 16s: Assessment and Management. London: National Institute for Health and Care Excellence (UK) Copyright (c) NICE, 2016.; 2016

31. Qaseem A, Wilt TJ, McLean RM, Forciea MA. Noninvasive treatments for acute, subacute, and chronic low Back pain: a clinical practice Guideline from the American College of Physicians. Ann Intern Med. 2017;166:514-30.

32. Wong JJ, Côté P, Sutton DA, Randhawa K, Yu H, Varatharajan S, Goldgrub R, Nordin M, Gross DP, Shearer HM, et al. Clinical practice guidelines for the noninvasive management of low back pain: a systematic review by the Ontario protocol for traffic injury management (OPTIMa) collaboration. Eur J Pain. 2017;21:201-16.

33. Bussieres AE, Stewart G, Al-Zoubi F, Decina P, Descarreaux M, Hayden J, Hendrickson B, Hincapie C, Page I, Passmore S, et al. The Treatment of Neck Pain-Associated Disorders and Whiplash-Associated Disorders: A Clinical Practice Guideline. J Manipulative Physiol Ther. 2016;39:523-564.e527.

34. Newman S, Steed L, Mulligan K. Self-management interventions for chronic illness. Lancet. 2004;364:1523-37.

35. Cote P, Cassidy JD, Carroll L. The treatment of neck and low back pain: who seeks care? Who goes where? Med Care. 2001;39:956-67.

36. Partner JD. Americans' perceptions of chiropractic. Washington: Gallup, Inc;; 2015.

37. Beliveau PJH, Wong JJ, Sutton DA, Simon NB, Bussières AE, Mior SA, French SD. The chiropractic profession: a scoping review of utilization rates, reasons for seeking care, patient profiles, and care provided. Chiropractic \& Manual Therapies. 2017; 25:35.

38. Puhl AA, Reinhart CJ, Injeyan HS, Tibbles A. Description of the case mix experienced by chiropractic students during a clinical internship. J Chiropr Educ. 2017:31:132-9.

39. Canadian Chiropractic Resources Databank (CCRD): National Report. A comprehensive inventory of practical information about Canada's licensed chiropractors. Toronto, Canada: The Canadian Chiropractic Association; 2011

40. Bussieres AE, Al Zoubi F, Stuber K, French SD, Boruff J, Corrigan J, Thomas A Evidence-based practice, research utilization, and knowledge translation in chiropractic: a scoping review. BMC Complement Altern Med. 2016;16:216.

41. Bussieres AE, Terhorst L, Leach M, Stuber K, Evans R, Schneider MJ. Selfreported attitudes, skills and use of evidence-based practice among Canadian doctors of chiropractic: a national survey. J Can Chiropr Assoc. 2015;59:332-48

42. Eilayyan O, Thomas A, Halle MC, Ahmed S, Tibbles AC, Jacobs C, Mior S, Davis C, Evans R, Schneider MJ, et al. Promoting the use of selfmanagement in novice chiropractors treating individuals with spine pain: the design of a theory-based knowledge translation intervention. BMC Musculoskelet Disord. 2018;19:328.

43. De Silva D. Evidence: helping people help themselves - a review of the evidence considering whether it is worthwhile to support self-management. London: The Health Foundation; 2011.

44. Rogers A, Kennedy A, Bower P, Gardner C, Gately C, Lee V, Reeves D, Richardson G. The United Kingdom expert patients Programme: results and implications from a national evaluation. Med J Aust. 2008;189:S21-4.

45. May S. Self-management of chronic low back pain and osteoarthritis. Nat Rev Rheumatol. 2010;6:199-209.
46. Briggs AM, Slater H, Bunzli S, Jordan JE, Davies SJ, Smith AJ, Quintner JL. Consumers' experiences of back pain in rural Western Australia: access to information and services, and self-management behaviours. BMC Health Serv Res. 2012;12:357.

47. Gordon K, Rice H, Allcock N, Bell P, Dunbar M, Gilbert S, Wallace H. Barriers to self-management of chronic pain in primary care: a qualitative focus group study. Br J Gen Pract. 2017;67:e209-17.

48. Straus S, Tetroe J, Graham I: Knowledge translation in health care: moving from evidence to practice. Second edn. Chichester, West Sussex, UK: John Wiley \& Sons; 2013.

49. Judith Hibbard, Helen Gilburt: Supporting people to manage their health: An introduction to patient activation. (Accuracy Matters ed. pp. 54. London; 2014:54.

50. Keogh A, Tully MA, Matthews J, Hurley DA. A review of behaviour change theories and techniques used in group based self-management programmes for chronic low back pain and arthritis. Man Ther. 2015;20:727-35.

51. Zhao FF, Suhonen R, Koskinen S, Leino-Kilpi H. Theory-based selfmanagement educational interventions on patients with type 2 diabetes: a systematic review and meta-analysis of randomized controlled trials. J Adv Nurs. 2017;73:812-33.

52. Foy R, Francis JJ, Johnston M, Eccles M, Lecouturier J, Bamford C, Grimshaw $J$. The development of a theory-based intervention to promote appropriate disclosure of a diagnosis of dementia. BMC Health Serv Res. 2007;7:207.

53. Timmerman L, Stronks DL, Huygen F. The design of a theory-based intervention to improve medication adherence in chronic pain patients. Curr Med Res Opin. 2017;33:1293-301.

54. Heath G, Cooke R, Cameron E. A theory-based approach for developing interventions to change patient Behaviours: a medication adherence example from Paediatric secondary care. Healthcare. 2015;3:1228-42.

55. French SD, Green SE, O'Connor DA, McKenzie JE, Francis JJ, Michie S, Buchbinder R, Schattner P, Spike N, Grimshaw JM. Developing theoryinformed behaviour change interventions to implement evidence into practice: a systematic approach using the theoretical domains framework. Implement Sci. 2012;7:38.

56. Atkins L, Francis J, Islam R, O'Connor D, Patey A, Ivers N, Foy R, Duncan EM, Colquhoun $\mathrm{H}$, Grimshaw JM, et al. A guide to using the theoretical domains framework of behaviour change to investigate implementation problems. Implement Sci. 2017;12:77.

57. Francis JJ, O'Connor D, Curran J. Theories of behaviour change synthesised into a set of theoretical groupings: introducing a thematic series on the theoretical domains framework. Implement Sci. 2012;7:35.

58. McCullough AR, Ryan C, O'Neill B, Bradley JM, Elborn JS, Hughes CM. Defining the content and delivery of an intervention to change AdhereNce to treatment in BonchiEctasis (CAN-BE): a qualitative approach incorporating the theoretical domains framework, behavioural change techniques and stakeholder expert panels. BMC Health Serv Res. 2015;15:342.

59. McGrady ME, Ryan JL, Brown GA, Cushing CC. Topical review: theoretical frameworks in pediatric adherence-promotion interventions: research findings and methodological implications. J Pediatr Psychol. 2015;40:721-6.

60. Dobson F, Bennell KL, French SD, Nicolson PJ, Klaasman RN, Holden MA, Atkins L, Hinman RS. Barriers and facilitators to exercise participation in people with hip and/or knee osteoarthritis: synthesis of the literature using behavior change theory. Am J Phys Med Rehabil. 2016;95:372-89.

61. Mosavianpour M, Sarmast HH, Kissoon N, Collet JP. Theoretical domains framework to assess barriers to change for planning health care quality interventions: a systematic literature review. J Multidiscip Healthc. 2016;9:303-10

62. Bussières AE, Al Zoubi F, Quon JA, Ahmed S, Thomas A, Stuber K, Sajko S, French $S$. Fast tracking the design of theory-based KT interventions through a consensus process. Implement Sci. 2015;10:18.

63. Cane J, O'Connor D, Michie S. Validation of the theoretical domains framework for use in behaviour change and implementation research. Implement Sci. 2012;7:37.

64. Tibbles AC, Jacobs C. Self-managment implementation at CMCC; 2017.

65. Hibbard JH, Mahoney ER, Stockard J, Tusler M. Development and testing of a short form of the patient activation measure. Health Serv Res. 2005;40:1918-30.

66. Hibbard J, Gilburt H. Supporting people to manage their health. An introduction to patient activation. London: The King's Fund; 2014

67. Rademakers J, Jansen D, van der Hoek L, Heijmans M. Clinicians' beliefs and attitudes toward patient self-management in the Netherlands; translation and testing of the American clinician support for patient activation measure (CS-PAM). BMC Health Serv Res. 2015;15:138. 
68. Prey JE, Qian M, Restaino S, Hibbard J, Bakken S, Schnall R, Rothenberg G, Vawdrey DK, Masterson Creber R. Reliability and validity of the patient activation measure in hospitalized patients. Patient Educ Couns. 2016;99:2026-33.

69. Schmaderer M, Pozehl B, Hertzog M, Zimmerman L. Psychometric properties of the patient activation measure in multimorbid hospitalized patients. J Nurs Meas. 2015;23:128-41.

70. What is OSCAR McMaster? [https://www.oscarhost.ca/whatisoscar]

71. SAS ${ }^{\otimes} 9.4$ Software [http://support.sas.com/software/94/index.html].

72. Charan J, Biswas T. How to calculate sample size for different study designs in medical research? Indian J Psychol Med. 2013;35:121-6.

73. Anderson JK, Wallace LM. Evaluation of uptake and effect on patientreported outcomes of a clinician and patient co-led chronic musculoskeletal pain self-management programme provided by the UK National Health Service. Br J Pain. 2018;12:104-12.

74. Skolasky RL, Mackenzie EJ, Riley LH 3rd, Wegener ST. Psychometric properties of the patient activation measure among individuals presenting for elective lumbar spine surgery. Qual Life Res. 2009;18:1357-66.

75. Dao XCJ, Blais-Hébert R, Duranleau L, Durivage M-P, Litowski J, Turbide J, Bussières AE. Complex regional pain syndrome: facilitating the use of selfmanagement strategies. Edorium J Disabil Rehabil. 2017;3.

76. Francis JJ, Johnston M, Robertson C, Glidewell L, Entwistle V, Eccles MP, Grimshaw JM. What is an adequate sample size? Operationalising data saturation for theory-based interview studies. Psychol Health. 2010;25:1229-45.

77. Bussieres AE, Patey AM, Francis JJ, Sales AE, Grimshaw JM, Brouwers M, Godin $\mathrm{G}$, Hux J, Johnston M, Lemyre L, et al. Identifying factors likely to influence compliance with diagnostic imaging guideline recommendations for spine disorders among chiropractors in North America: a focus group study using the theoretical domains framework. Implement Sci. 2012;7:82.

78. Francis JJ, Tinmouth A, Stanworth SJ, Grimshaw JM, Johnston M, Hyde C, Stockton C, Brehaut JC, Fergusson D, Eccles MP. Using theories of behaviour to understand transfusion prescribing in three clinical contexts in two countries: development work for an implementation trial. Implement Sci. 2009;4:70

79. Michie S, Johnston M, Francis J, Hardeman W, Eccles M. From theory to intervention: mapping theoretically derived Behavioural determinants to behaviour change techniques. Appl Psychol. 2008;57:660-80.

80. Michie S, Richardson M, Johnston M, Abraham C, Francis J, Hardeman W, Eccles MP, Cane J, Wood CE. The behavior change technique taxonomy (v1) of 93 hierarchically clustered techniques: building an international consensus for the reporting of behavior change interventions. Ann Behav Med. 2013;46:81-95.

81. Rx for Change database [https://www.cadth.ca/resources/rx-for-change/ database/intervention?id=38]

82. Hurley DA, Murphy LC, Hayes D, Hall AM, Toomey E, McDonough SM, Lonsdale C, Walsh NE, Guerin S, Matthews J. Using intervention mapping to develop a theory-driven, group-based complex intervention to support self-management of osteoarthritis and low back pain (SOLAS). Implement Sci. 2016;11:56.

83. Vernooij RW, Willson M, Gagliardi AR. Characterizing patient-oriented tools that could be packaged with guidelines to promote self-management and guideline adoption: a meta-review. Implement Sci. 2016;11:52.

84. Schipper K, Bakker M, De Wit M, Ket JCF, Abma TAJIS. Strategies for disseminating recommendations or guidelines to patients: a systematic review. Implement Sci. 2016;11:82.

85. Weiner BJ, Lewis CC, Stanick C, Powell BJ, Dorsey CN, Clary AS, Boynton MH, Halko H. Psychometric assessment of three newly developed implementation outcome measures. Implement Sci. 2017;12:108.

86. Gutnick D, Reims K, Davis C, Gainforth H, Jay M, Cole S. Brief action planning to facilitate behavior change and support patient selfmanagement. J Clin Outcomes Manag. 2014;21:17-29.

87. Lorig KR, Ritter P, Stewart AL, Sobel DS, Brown BW Jr, Bandura A, Gonzalez VM, Laurent DD, Holman HR. Chronic disease self-management program: 2-year health status and health care utilization outcomes. Med Care. 2001;39:1217-23.

88. Gutnick D, Reims K, Davis C, Gainforth H, Jay M, Cole S. Brief action planning to facilitate behavior change and support patient selfmanagement. J Clin Outcomes Manag. 2014;21.

89. Rx for Change database 2011 [ https://www.cadth.ca/rx-change].

90. Michie S, Johnston M, Francis J, Hardeman W, Eccles M: From Theory to Intervention: Mapping Theoretically Derived Behavioural Determinants to Behaviour Change Techniques 2008, 57:660-680.
91. McCulloch DK, Davis C, Austin BT, Wagner EH. Constructing a bridge across the quality chasm: a practical way to get healthier, happier patients, providers, and health care delivery systems. Diabetes Spectrum. 2004;17:92-6.

92. Gagliardi AR, Legare F, Brouwers MC, Webster F, Badley E, Straus S. Patientmediated knowledge translation (PKT) interventions for clinical encounters: a systematic review. Implement Sci. 2016;11:26.

93. Coudeyre E, Givron P, Vanbiervliet W, Benaim C, Herisson C, Pelissier J, Poiraudeau $S$. The role of an information booklet or oral information about back pain in reducing disability and fear-avoidance beliefs among patients with subacute and chronic low back pain. A randomized controlled trial in a rehabilitation unit. Ann Readapt Med Phys. 2006;49:600-8.

94. Bandura A. Self-efficacy: toward a unifying theory of behavioral change. Psychol Rev. 1977;84:191-215.

95. Wensing M, Vedsted P, Kersnik J, Peersman W, Klingenberg A, Hearnshaw $H$, Hjortdahl P, Paulus D, Kunzi B, Mendive J, Grol R. Patient satisfaction with availability of general practice: an international comparison. Int J Qual Health Care. 2002;14:111-8.

96. Stimson GV. Obeying doctor's orders: a view from the other side. Soc Sci Med. 1974;8:97-104.

97. Street RL Jr, Makoul G, Arora NK, Epstein RM. How does communication heal? Pathways linking clinician-patient communication to health outcomes. Patient Educ Couns. 2009;74:295-301.

98. Hoving C, Visser A, Mullen PD, van den Borne B. A history of patient education by health professionals in Europe and North America: from authority to shared decision making education. Patient Educ Couns. 2010;78:275-81.

99. Straus SE, Tetroe J, Graham ID: The Knowledge-to-Action Cycle. In Knowledge Translation in Health Care: Moving from Evidence to Practice. Blackwell Publishing Ltd; 2009: 59-181.

100. Mahler HI, Kulik JA, Tarazi RY. Effects of a videotape information intervention at discharge on diet and exercise compliance after coronary bypass surgery. J Cardpulm Rehabil. 1999;19:170-7.

101. Welch V, Petkovic J, Pardo Pardo J, Rader T, Tugwell P. Interactive social media interventions to promote health equity: an overview of reviews. Health Promot Chronic Dis Prev Can. 2016;36:63-75.

102. McDonald HP, Garg AX, Haynes RB. Interventions to enhance patient adherence to medication prescriptions: scientific review. Jama. 2002;288:2868-79.

103. Nieuwlaat R, Wilczynski N, Navarro T, Hobson N, Jeffery R, Keepanasseril A, Agoritsas T, Mistry N, lorio A, Jack $\mathrm{S}$, et al: Interventions for enhancing medication adherence. Cochrane Database Syst Rev 2014:Cd000011.

104. Kripalani S, Yao X, Haynes RB. Interventions to enhance medication adherence in chronic medical conditions: a systematic review. Arch Intern Med. 2007;167:540-50.

105. Anthony Tibbles, Craig Jacobs: CMCC Curriculum. (Owis Eilayyan, Andre Bussieres eds.); 2017.

\section{Publisher's Note}

Springer Nature remains neutral with regard to jurisdictional claims in published maps and institutional affiliations.
Ready to submit your research? Choose BMC and benefit from:

- fast, convenient online submission

- thorough peer review by experienced researchers in your field

- rapid publication on acceptance

- support for research data, including large and complex data types

- gold Open Access which fosters wider collaboration and increased citations

- maximum visibility for your research: over $100 \mathrm{M}$ website views per year

At $\mathrm{BMC}$, research is always in progress.

Learn more biomedcentral.com/submissions 